\title{
Groupwork with HIV positive drug misusers in prison
}

\author{
Julian Pugh, BA, CQSW, Senior Probation and Welfare Officer, Probation and Welfare \\ Service, Smithfield Chambers, Smithfield, Dublin 7, Ireland.
}

\begin{abstract}
Objective: The groupwork programme in this study sought to engage HIV positive drug misusers within a prison setting in order to introduce ideas and information, and by so doing promote desired behavioural changes in terms of risk behaviour and drug addiction. Such an effort was also seen as a strategy to help prisoners cope with imprisonment and to prepare them for the demands that they might face following release.
\end{abstract}

Method: Various methods of giving information and discussion were employed in order to influence members' views and behaviour. The interactions between group members were recorded using a modified version of Bale's Interaction Process Analysis Instrument during each session. In this way it was possible to analyse individual member's functioning as well as that of the whole group over the duration of the programme.

Results: While significant changes in members' views and behaviour could not be proven, an analysis of the group's communication, control, evaluation and decision making profiles reflected effort and engagement in tackling the subject inputs. Analysis of individual member's contributions was, however, open to more speculative interpretation.

Conclusion: The positive response from group members, combined with an analysis of the results suggests that the approach adopted in the programme was an encouraging step in devising an acceptable and relevant educational and treatment strategy in dealing with this usually reluctant client group, many of whom are unresponsive to traditional treatment methods.

Key words: HIV; AIDS; Prison; Opiate abusers; Heroin misusers; Groupwork; Probation.

\section{Introduction}

The Segregation Unit within Mountjoy Prison accommodates 45 HIV positive prisoners who, following voluntary testing, arc housed in a separate accommodation area with its own catering and medical facilities. The Annual Report on Prisons $1986^{1}$ outlines the basis for this policy. The Advisory Committee on Communicable Diseases in Prison, ${ }^{2}$ whose report was published in May 1993, recommended that the practice of automatic segregation of HIV positive prisoners be ended and that a major evaluation of existing policy be undertaken. A few months later in October 1993 the Council of Europe ${ }^{3}$ made recommendations concerning transmissible diseases and their effect on criminological and prison issues. In effect, seropositive prisoners should not be regarded differently to those of a similar health status in the community. On September 29, 1994 the Minister for Justice announced that the policy of segregation would cease to have effect from January 1, 1995. Such separation can accentuate some of the problems associated with identifying seropositivity; for example, whether to test or not and raise problems concerning the confidentiality of prisoners' HIV status. The vast 
majority of prisoners within the unit are intravenous drug misusers, who to a limited extent are still able to obtain a supply of illicit drugs. This phenomenon is to be found in prisons in most other countries and accordingly prisoners are subject to the risks and dynamics that such illicit drug misuse creates - sharing of injecting equipment and the interpersonal dynamics of engaging in such activity within a prison setting.

Carvel and Hart ${ }^{4}$ substantiate this view, suggesting that drug misusers engage in high risk behaviour whether inside or outside prison. Skoler and Dargan ${ }^{5}$ describe the response of US administrators in terms of managing AIDS issues within prisons. The decisions of US administrators have been upheld against prisoner challenges "as to whether to segregate or not, whether to test or not, what kinds of medical treatment and prisoner protection policies are warranted and can be restricted for health and security management purposes". However, the management of the HIV positive prisoner should take place within a setting which appreciates the contribution from other disciplines in devising and managing acceptable regimes which are responsive to new ideas, situations and medical advances. The prisoner's perspective must always be considered.

Prison life is characterised by high stress levels with regular incidents of self harm among prisoners. Prisoners' obsession with the possibility of early release under the Temporary Release Rules together with a continuous assessment of the chances of fellow inmates vis-a-vis themselves of such a release rises stress levels further. The effects of illness and the spectre of death are haunting preoccupations for most prisoners. Individuals who on previous occasions have been able to serve time prior to diagnosis, may now be unable to cope with the prospect of their early death. The scene is completed by a significant core group of recidivists who, trapped in a vicious circle of drug addiction, crime and imprisonment, are regularly committed to prison.

Groupwork programmes rarely lend themselves to quantitative analysis and frequently rely on subjective reporting techniques to comment on their effect on the individuals involved. While claims of confirmed attitude or behaviour change would be unrealistic and unprovable, it would seem that efforts to engage individuals via a groupwork process, in order to promote a greater acceptability to new ideas, education and opinion, are valid. It is within such a context that the programme which is the subject of this paper was formed. The purpose of the groupwork programme was to introduce ideas and information in new forms which, via the use of prisoner peer relations, would make those ideas more acceptable to such individuals and, accordingly, more likely to produce desired behavioural changes in terms of risk behaviour and drug addiction.

Difficulties can arise in the implementing of groupwork programmes within prison settings as they can raise prisoners' expectations of early release and therefore affect their motivation in terms of group membership. Other problems relate to the requirement not to promote the values of a deviant subculture or to allow unacceptable behaviour and challenge to occur due to a lack of effective group leadership. The latter point has obvious implications for safety and security within the institution.

In planning such a groupwork programme, which includes HIV/AIDS and drug addiction issues, the group leaders should have an accurate and adequate knowledge base including an appreciation of the perspectives and models adopted by various relevant treatment and counselling agencies. Murphy ${ }^{6}$ provides such an overview of the HIV and drug treatment issues and policies in the Irish context. Pearson ${ }^{7}$ outlines the difficulties associated with variations in agency response and inter-agency conflict.

Madden, Swinton and Gunn ${ }^{8,9}$ undertook two surveys relating to drug dependence in male and female prisoners. They suggested a need for treatment initiatives throughout the system and concurred with the importance of liaison work in the preparation for release of 
such prisoners as outlined in the Home Office Policy statement on through care of drug misusers in the prison system. ${ }^{10}$ It is axiomatic that previous and potential clients are correctly or incorrectly influenced by the perceived attributes or otherwise of each agency or treatment approach. While much inter-agency cooperation and liaison does exist in connection with drug misusers, such relations should be examined and improved as many shared clients oscillate between agencies. The practice approach in the groupwork programme outlined in this paper sought to view the existing provision of services and issues from a bottom-up client perspective rather than a top-down agency perspective.

\section{Programme}

Session 1: Introduction - discussion of contract, proposed programme outline and other initial issues, eg. confidentiality.

Session 2: Addiction - discussion of the addiction models to which members ascribed, drawing of links between drugs, crime and background addiction.

Session 3: HIV Facts and Feelings Quiz and discussion format - exploration of members' existing knowledge, correction of erroneous beliefs and acquisition of new information, discussion of various attitudes held and how these affect families.

Session 4: Coping in prison - examination of issues and use of coping strategies, recognition of stress associated problems and discussion of possible coping mechanisms, allow for the raising of illness and death issues.

Session 5: Preparation for release - preparation within the prison, problems encountered on release, drug abstinence and treatment options, coping strategies, how to avoid crime.

Session 6: Concluding session and party - review and evaluation of the programme.

\section{Method}

The programme consisted of six weekly group sessions, each of 90 minutes. A social learning theory/task centred theoretical base governed the structure of the sessions. Social learning theory relates to the patterns of behaviour which an individual learns in coping with the environment. It focuses on the interaction between the individual and the system of which he is part. In this way it may provide individuals with a partial explanatory framework in which to make sense of at least some aspects of their circumstances. Particular attention was given to the preparation, recording and management of each session in accordance with accepted groupwork practice. Clients were required to sign a contract requiring compliance with group rules and to give a commitment to attend all sessions.

The leadership roles within the group were functional in terms described by Ross. ${ }^{11}$ That is, functional in determining the tasks of the group, by getting information, collecting opinions and summarising what has been achieved. Also, functional in terms of group maintenance, by eliciting information, valuing members' contributions and summarising what had been achieved.

While several instruments were used to record the group's activities, only one lent itself to a form of quantitative analysis. The grid displayed in the tables allowed for an examination of group members contributions within sessions according to the 19 types of interaction process category. The grid was extended by Douglas ${ }^{12}$ from observation categories devised by Bales. ${ }^{13}$ The latter interaction process analysis is a complex methodology based on 12 interaction process categories (IPCs). Bales' theoretical rationale is an idealised problem solving process in which an alternating emphasis is chartered according to the categories of 
IPCs used. These may be in the 'Social-emotional area: positive', the 'Social-emotional area: negative' or the 'Task area: neutral' areas of group functioning. When group attention is given to one area, strains are created in the other areas. For example, when a group concerns itself with task issues, strains occur in the social and emotional dynamics of the group and consequently attention changes towards addressing the relief of those strains.

Table 2 displays the combined IPC profiles of the group split between programme halves. It also shows the social-emotional and task oriented areas in which the interaction of group members can be assigned. These areas may be further divided into positive and negative and then further divided into six problem areas. The two problem areas not included relate to those of tension reduction and reintegration; because Douglas' qualitative extension to the instrument did not include the original IPCs for these areas. The assignments were made by the two group leaders after each session, according to the contribution types made in general over the duration of each session. In ideal circumstances the assignments should be recorded every 10 minutes.

To analyse the effect of the programme, data can be examined in relation to the 'Task area: neutral' of group activities which comprise of categories 4 to 9. Within the profile, potential problem classifications may be identified. That is, categories 8 and 9 relate to potential problems of communication, categories 6 and 7 relate to potential evaluation problems. The rate of activity in category 9 indicates the amount of interaction which the group devotes to attempted solution of the problems of perception and communication.

However, such an index is not absolute as it will vary depending upon many conditions. Categories 2 and 16 relate to potential decision making problems and fall into the 'Social-emotional area: positive'.

In themselves any assignments attached to these categories do not demonstrate the effectiveness of profiles such as that of perception and communication. However, the ratio between the two calculated for each programme half does provide an 'index of difficulty'. Bales rests this index on the assumption that there is a normal balance between the interactions in the paired categories. For example, the difficulty of communication index comprises of IPCs 8 and 9 and that any changes in the ratio between them demonstrates imbalance. If category 9 (seeking or requesting information) increases without a comparable increase in category 8 (gives information) then an unfavourable difficulty in communication is evident. The other indexes of difficulty are constructed in a similar fashion.

$$
\text { Index of difficulty of communication }=\frac{9}{9+8}
$$

The numerator is included in the denominator to ensure all values will be percentages between 0 and 100. As the percentage increases it is assumed that difficulty in communication is increasing and vice versa. The absolute values of the indexes have no other relevance as they are constructed solely to compare one part of the groupwork programme with another. Bales built another index onto the index of difficulty of communication but this paper's use of Douglas' expanded IPCs does not allow this to be calculated. Such indexes represent a highly idealised and schematised process. Whilst it is a conceptually simplified process, Bales believed that it contained great theoretical relevance and power. In view of Douglas' qualitative extension to Bales' IPCs this paper is limited in the depth of analysis possible. It should be noted in Table I that the session assignments indicate the number of the session attended (between one and six) placed in an appropriate IPC cell. The frequency of each category utilised per session was not recorded. 


\section{Results}

Table I displays the interaction process categories (IPCs) recorded by session number as raw data. It can be observed that members 1, 3 and 10 expanded their range of IPCs used over the life of the life of the group. Member 7 also expanded his limited IPCs during the latter part of the programme. It should also be noted that members 2, 4 and 5 contracted theirs. By expansion it is meant that the range of categories used is increased over all the programme sessions. It does not mean counting the number of interactions per group member for each session. Some categories appear in both programme halves, whilst others appear in one half only.

It should be noted that not all members attended all sessions. This has implications regarding their experience particularly in relation to the stage of the group's growth which is likely to be enhanced over time. Members 6 and 8 attended the first three and first two group sessions respectively. Similarly members 3 and 4 attended less sessions in the second programme half. It can be observed that members 1, 2 and 4 displayed a difference in the range of IPCs used in the second half of the programme as opposed to the first. It can also be seen that members 3 and 7 displayed a greater range of IPCs in the second programme half, particularly so if an allowance is made for the fact that they attended three sessions in the first programme half and less in the second programme half.

Table 2 displays the combined IPCs for all members split between programme halves. The data is expressed as a percentage of the total number of contributions possible (ie. 57) per group member. Table 3 represents an interpretation

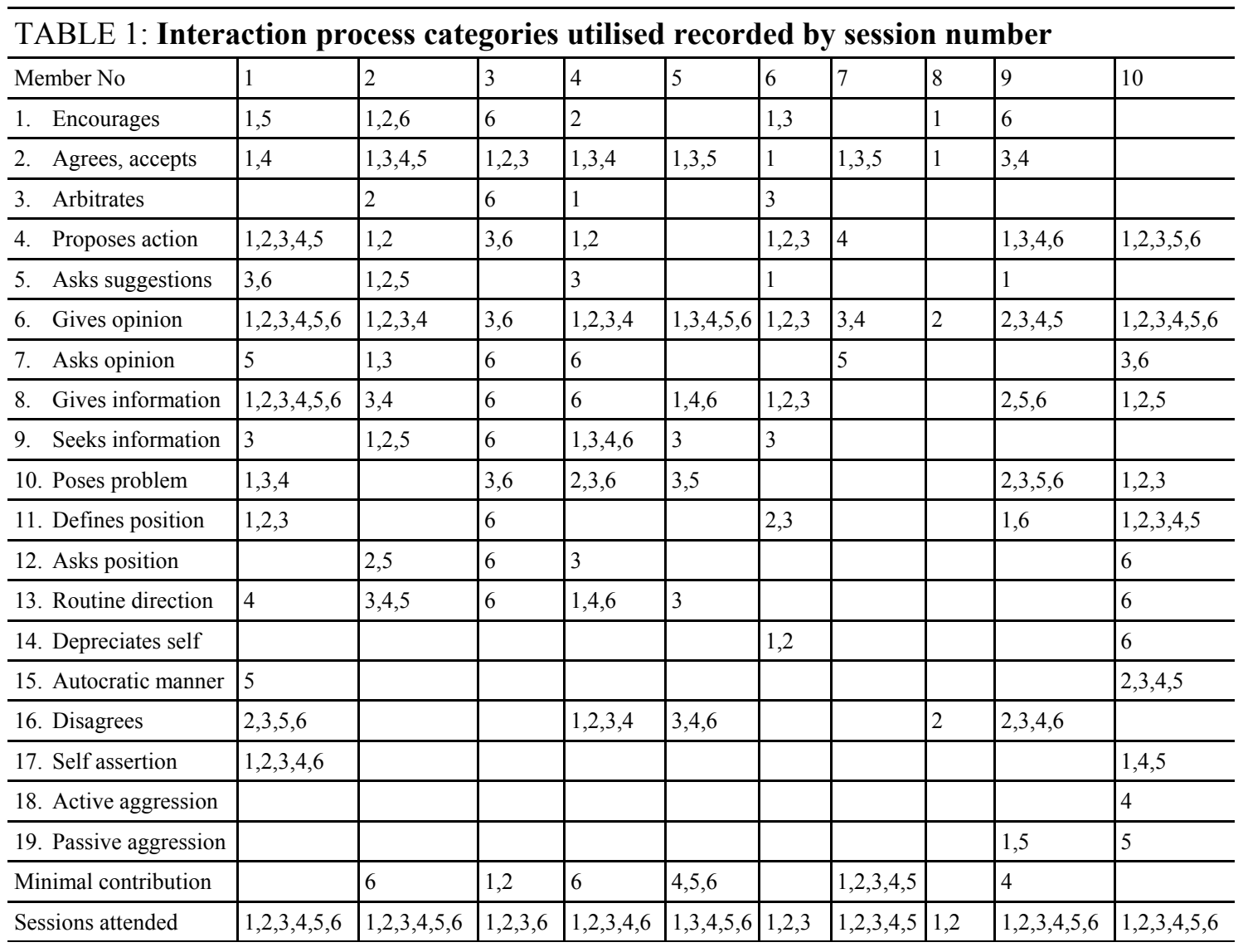


TABLE 2: Interaction profile of all members

TABLE 2: Interaction profile of ail members

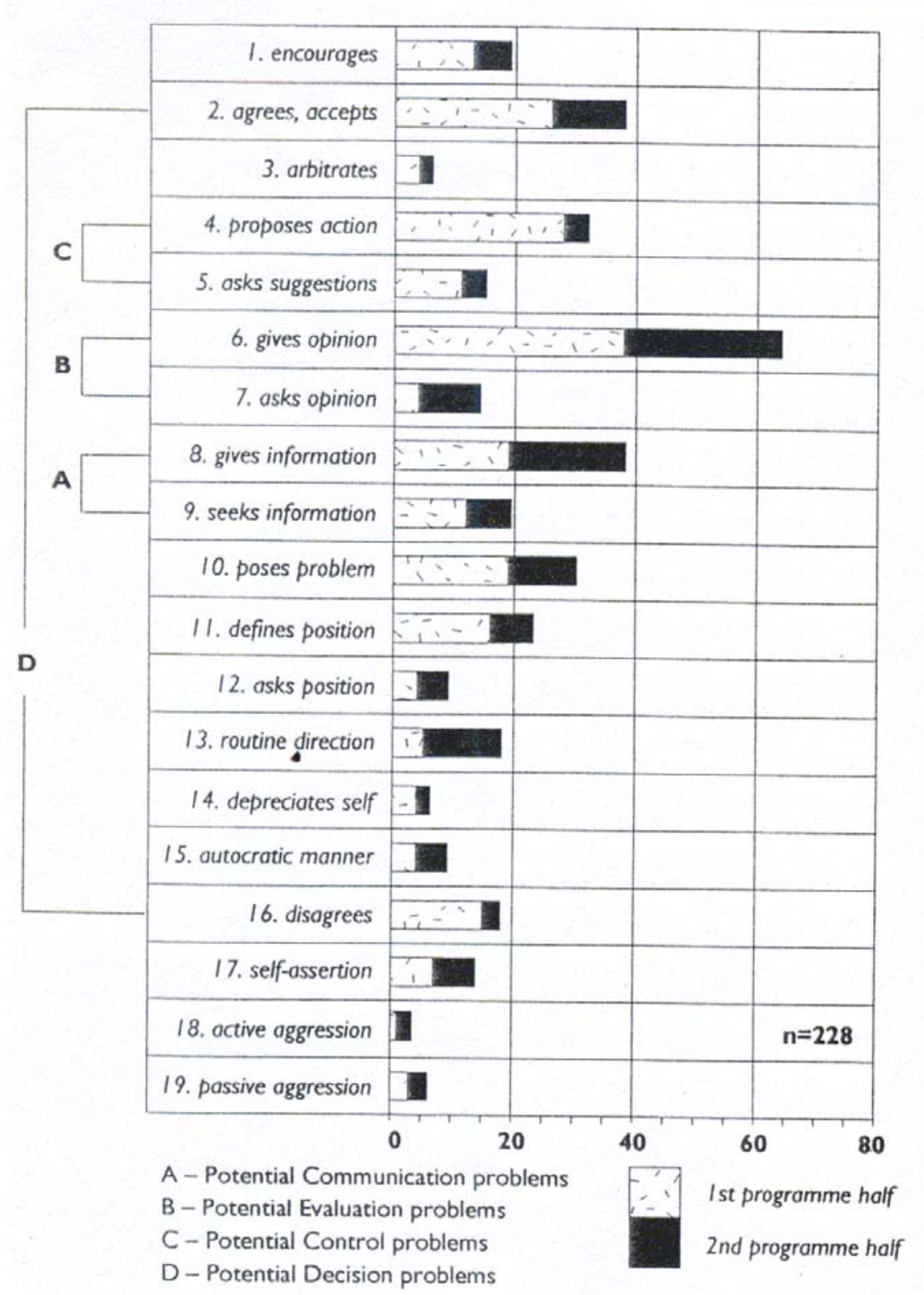

TABLE 3: Indexes of difficulty and the percentage difference between programme halves

\begin{tabular}{lcccc}
\hline Index & $\begin{array}{c}\text { IPC category } \\
\text { number }\end{array}$ & first half & second half & difference \\
$\begin{array}{l}\text { 1. Difficulty of } \\
\text { communication }\end{array}$ & $\frac{9}{++8}$ & 38 & 26 & -12 \\
$\begin{array}{l}\text { 2. Difficulty of } \\
\text { evaluation }\end{array}$ & $\frac{7}{7+6}$ & 11 & 25 & +14 \\
$\begin{array}{l}\text { 3. Difficulty of control } \\
\begin{array}{l}\text { 4. Difficulty making } \\
\text { decisions }\end{array}\end{array}$ & $\frac{5}{1+4}$ & 28 & 22 & -6 \\
\hline
\end{tabular}


of Table 2 showing the construction of the indexes of difficulty. The index of difficulty of communication and the index of difficulty of control display a decreasing percentage indicating a decreasing difficulty in these areas of the group's functioning between programme halves. The index of difficulty of evaluation and the index of difficulty in making decisions show an increased percentage difference and therefore indicate an increasing difficulty in these areas of group functioning.

\section{Discussion}

The programme outline was adopted by the members and a final consensus indicated that the experience had been beneficial and successful. The programme reflected issues that had already been identified following individual counselling with prisoners. The discussion of these issues outside a dyadic but within a group setting proved to be an effective method of working from a probation officer's perspective. It freed him from the usual obsession that prisoners have regarding their temporary release prospects and the influence that the former is thought to have in relation to those prospects. The probation officer's position within the group was accepted, after some discussion concerning confidentiality issues. Several uniformed staff also observed the potential use of the group in relieving some of the interpersonal difficulties and grouses among prisoners.

The prisoners accepted the conditions of the contract. Over the life of the group it became apparent that some items of clandestine information known to prisoners only would not be verbally raised in the group although the awareness of such information would impinge upon the dynamics of the group. A conspiracy existed among members to keep such items from the leaders, although outside the group, in a one to one talk with a leader, those items of information were sometimes referred to. This reflected the legitimate status of the leaders in terms of the members deviant subculture and the lack of trust that they would have regarding the implications of such a disclosure. This also has implications for the sort of challenge any member could make on another without breaking the rules of inmate conduct. Similarly challenges to status positions between members were not made within the group context.

Session three involved the use of the Checking out facts and feelings quiz on HIV and AIDS. ${ }^{14}$ Group members displayed a high level of knowledge concerning the methods of HIV transmission and entered enthusiastically into a discussion of the issues involved. Evaluation of the scores was not possible as members preferred to keep and not disclose their quiz sheets. The completion of Preston-Shoot's ${ }^{15}$ weekly group recording form was not met with enthusiasm and may have reflected a suspicion of tests or forms as well as an embarrassment concerning their ability to complete them. Weekly and final programme evaluation took the form of a discussion which reflected accepting and positive views by members though with little analysis or appreciation of views other than their own. Members avoided any discussion of serious illness or death to the point that they were regarded as taboo.

While Table 3 indicates an increasing difficulty for the group in making decisions, Douglas informs us of the importance of members understanding and being able to use decision making processes within groups, as it is an effective way of maintaining interest in a group's activities. It is also suggested, by Bownes et al, ${ }^{16}$ that a narrow emphasis on information ignores the powerful effect other factors may have on an individual's motivation to change his behaviour. In particular they suggest that the effectiveness of AIDS education is likely to be influenced by the cognitions of the population at which it is aimed. It is suggested that the groupwork programme in this paper goes some way towards harnessing some of those other factors by influencing the behaviour of group members who have already had their cognitions influenced by social, cultural and now disease factors. ${ }^{17,18}$

Any interpretation of the results must be couched in tentative terms bearing in mind the medium of data collection and the simplicity of Bales' conceptual structure. Furthermore 
allowance has also to be made for the overall recording of session assignments in terms of one assignment per session as opposed to the 10 minute intervals via a special machine used by Bales. Changes in the decision making dynamics of the group, as noted in the changes of the range of interaction process categories used by members, is likely to increase the receptiveness of members towards desired behaviour change. It is also likely that members were more receptive to drug and HIV/AIDS information than previously. It also indicated changes within group dynamics occurring during the life of the group. That is, some members who displayed a narrower range of IPC utilisation during the first programme half displayed a greater range in the second half and vice versa. One may also speculate regarding reasons why members increase or decrease their range of IPC use which may be due to other factors, such as interest, confidence or ability to articulate. It was observed that some of the more vocal group members during the first programme half were less vocal and utilised less IPCs in the second half. In particular groupwork theories about growth and processes are also likely to have an effect upon individual members. For example, Schutz ${ }^{19}$ describes the effect of threat and trust needs in relation to group development and suggests a process by which groups proceed through stages of dealing with inclusion, control and then affection issues.

Table 1 indicates that not all members attended all sessions due to hospital appointments and unexpected visits from relatives. Unequal attendance between programme halves has obvious implications for the balanced interpretation of results. Members 6 and 8 did not attend any sessions in the second programme half. If their assignments were excluded, the first half total of IPCs utilised in one programme half only would be 14, and 18 for the second half. This would indicate an increased difference in the range of IPCs used solely in the second programme half only. One must also consider that group members were subject to other influences and experiences within the prison which could have an effect upon them. However, given the negative affects of prison in the area of interpersonal change under examination, positive extraneous variables are likely to be minimal.

The results displayed in Table 3 may support the suggestion that communication improves or differs over the life of the group in that some variation occurs in some members use of IPCs. One could hypothesise that the increased difficulty in decision making could be due to members attempts to relate the subject matter and discussion in terms of their own needs for personal change. If so, this suggests an effort in problem resolution, which in itself is a desired objective in any treatment initiative with HIV positive drug addicts.

One may be tempted to attach other hypotheses to explain the increasing or decreasing trends in indexes of difficulty. For example, while communication tends to improve over time in most groups the increasing difficulty demonstrated by the index of difficulty of evaluation might be construed as good effort in terms of problem resolution as set by the subject matter in each session viz-a-viz their own drug misuse and criminality. This paper is an attempt to assess the efforts of groupwork practice other than in a descriptive and qualitative way; accordingly the use of such methods lay one open to much methodological criticism. Perhaps there should be a call for therapists to commit themselves to a greater degree of shared quantifiable recording. Then perhaps, greater understanding and co-ordination would occur when trying to demonstrate the effectiveness of such educational and therapeutic processes.

Overall, group members did express a positive response to having engaged in such an experience which was also confirmed during discussions with individuals after the programme was completed. I am inclined to accept such comments although I would be aware of the possible diversion effects of such a programme within a monotonous setting. I would also be aware of the possible desire to please the probation officer.

One frequently discerns an expressed logic concerning AIDS information dissemination which creates an illusion that if information is given, it will to a varying degree be absorbed. When engaging drug misusers such a perspective is misplaced as also is the 
perception that drug misusers belong to one or two generalised groups. McKeganey ${ }^{20}$ commented on "the enormous variability in individual drug injector's responses which in itself should undermine any notion of typical injectors".

It is argued that groupwork is an effective method of engagement with drug misusers of various views who might not ordinarily refer themselves for education or treatment. By entering the work of the drug addict, from his own perspective, while retaining the integrity and knowledge base of a professional worker, one obtains a greater understanding of the deviant subculture together with its own particular relations and structure. Groupwork was found not only to be possible, but welcomed by the prisoners involved.

\section{Acknowledgements}

The groupwork programme in this paper was one of many programmes conducted within Mountjoy Prison. I fully acknowledge and appreciate the contribution of all the coleaders that I have worked with in several groupwork programmes. I also appreciate the advice, assistance and support of the uniformed staff. Most of all I thank the prisoners with whom I shared such enlightening experience.

\section{References}

1. Annual report on prisons and places of detention. Dublin: Dublin Stationery Office, 1986.

2. Report of the Advisory Committee on Communicable diseases in prison. Dublin: Dublin Stationery Office, 1993.

3. Council of Europe, recommendation No. R(93)6, concerning prison and the criminological aspects of the control of transmissible diseases including AIDS and related health problems in prison.

4. Carvel ALM, Hart GJ. Risk behaviours for HIV infection among drug users in prison. BMJ 1990; 300: 1383-4.

5. Skoler DL, Dargan RL. AIDS in prisons, administrator policies, inmate protests and reactions from the Federal Bench. Federal Probation 1990; L1V:,2.

6. Murphy I. HIV and drug treatment: issues and policies. AIDS Inform 1990; 2:1.

7. Pearson G, Oilman M, McIvers S. Young people and heroin: an examination of heroin use in Northern England: a report to the Health Education Council. London:

Gower, 1987.

8. Madden A, Swinton M, Gunn J. Women in prison and use of illicit drugs before arrest. BMJ 1990,301:1133.

9. Madden A. Swinton M, Gunn J. Drug dependence in prisoners. BMJ 1991; 302:880.

10. Home Office. Policy statement on the through care of drug misusers in the prison system.

London: Home Office Prison Department, 1988.

11. Douglas T. Groupwork practice. London: Tavistock. 1976.

12. Bales RE. Interaction process analysis. Reading (MA): Addison-Eesley, 1950.

13. Ross S, Thorpe A. Programming skills in groupwork. Groupwork 1988; 2.

14. Checking out facts and feelings quiz on HIV and AIDS. Unknown Australian source.

15. Preston-Shoot A. A model for evaluating groupwork. Groupwork 1988; 2.

16. Bownes IT, O'Gorman EC, Dinsmore WW. Factors influencing perception of risk of HIV acquisition among male heterosexual STD clinic attenders. Ir J Psychol Med 1990; 7: 94-100.

17. Donovan J. We don't buy sickness, it just comes. London: Gower. 1988.

18. Alcorn K. Illness, metaphor and AIDS. In: Aggleton PJ, Homans H, eds. Social aspects of AIDS. London: Falmer Press, 1988.

19. Schutz WC. FIRO: A three dimensional theory of interpersonal operations. New York: Holt Rinehart and Winston; 1958.

20. McKeagney N. Being positive: drug injectors experience of HIV infection. Glasgow: University of Glasgow Department of Child Health and Obstetrics, 1989. 